\title{
La no regulación ambiental: contaminación industrial del río Santiago en Jalisco
}

Cindy McCulligh

La contaminación del río Santiago en el estado de Jalisco, México, ha generado un conflicto socioambiental por las afectaciones a la salud y el bienestar de la población aledaña. A pesar de que una planta tratadora de aguas negras de la Zona Metropolitana de Guadalajara ha mejorado las condiciones del río, persiste la problemática de las descargas industriales. La deficiente legislación en materia de control de descargas asociada a su escasa aplicación favorecen la persistente contaminación del Santiago por los vertidos industriales.

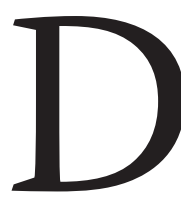

esde hace décadas, la espectacular caída de la espumosa y nauseabunda cascada del río Santiago, por el Salto de Juanacatlán, ha despertado la indignación y la exigencia ciudadanas. La escena del río contaminado, en particular la cascada, ha sido reiteradamente reproducida en los periódicos de Guadalajara. En 2012, Greenpeace México utilizó esa imagen como parte de una campaña de denuncia sobre ríos tóxicos, cuando valientes voluntarios provistos de equipo de protección se metieron al río debajo del salto en canoas inflables casi rebasadas por la espuma blanca. Esa imagen se ha transformado, parcialmente, a partir de mayo de 2012, cuando empezó a operar una primera planta de tratamiento para las voluminosas descargas de la Zona Metropolitana de Guadalajara en la Cuenca El Ahogado. Con excepción de la época de lluvias, cuando la planta no alcanza a tratar todas las aguas generadas, ya no se aprecia la contaminación más visible, generadora de las espumas tantas veces grabadas y fotografiadas. Sin embargo, permanecen sin ser atendidas otras fuentes de contaminación del río, notoriamente los efluentes del Corredor Industrial Ocotlán-El Salto, ya que la planta recibe sólo los vertidos municipales.

La contaminación del Santiago en los municipios de El Salto y Juanacatlán, Jalisco, ha propiciado un conflicto socioambiental debido a las afectaciones en la salud y el bienestar de la población aledaña, además de la mortandad de peces en el río desde 1973. ${ }^{1}$ En 1989, Elías González afirmaba que el Santiago se había con- 


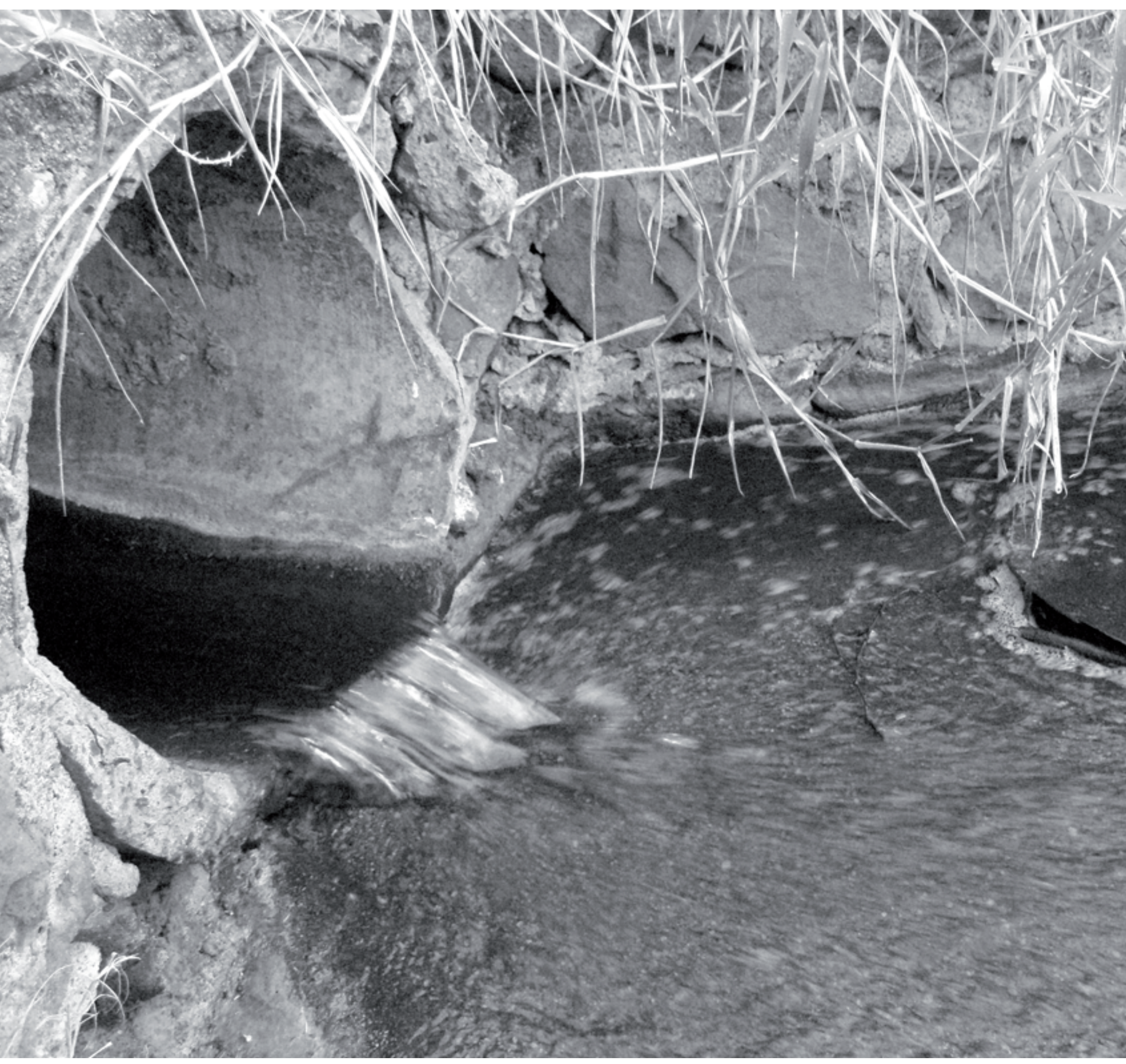


vertido en «un canal de desechos industriales que ha acabado con la fauna y con la posibilidad de uso de sus aguas [para cualquier otro propósito]». ${ }^{2}$ Desde 2001, han surgido varias organizaciones locales que exigen el saneamiento del río y la protección de la salud de los habitantes. Estas agrupaciones se han articulado con organizaciones y redes locales, nacionales e internacionales para denunciar las condiciones del río y demandar la acción del gobierno. ${ }^{3}$ En este breve artículo, pretendo reseñar cómo la deficiente legislación en materia de control de descargas a aguas nacionales, así como su escasa aplicación, favorecen la prolongada contaminación del Santiago, en particular por vertidos industriales.

\section{El CAUCe De La CloACA}

En su trayecto de 562 kilómetros, desde el lago de Chapala hasta el océano Pacífico, cerca de San Blas, Nayarit, el río Santiago es receptor de aguas residuales municipales sin tratamiento (o con niveles bajos de tratamiento), sobre todo de los vertidos en la Zona Metropolitana de Guadalajara (ZMG), además de las descargas industriales, lixiviados de «rellenos sanitarios» ubicados en su cercanía y escorrentía agrícola. Habitan en la cuenca del río Santiago alrededor de 7.5 millones de personas, con la mayor concentración en la ZMG, donde la población es superior a 4.4 millones de habitantes. ${ }^{4}$ A principios de 2012, los niveles de tratamiento de $\operatorname{los} 8.3 \mathrm{~m}^{3}$ por segundo de aguas residuales municipales de la ZMG no rebasaban el 1\%, según datos del Sistema Intermunicipal para los Servicios de Agua y Alcantarillado (SIAPA), que presta servicios en los cuatro municipios principales de la zona. Desde mayo de 2012 opera la primera de las dos macro-plantas de tratamiento de la ZMG, la Planta de Tratamiento de Aguas Residuales (PTAR) El Ahogado, para tratar 20\% de las descargas domésticas de la ZMG, sin dar tratamiento a las descargas de origen industrial. El otro $80 \%$ de las aguas negras de la ZMG será tratado en la PTAR Agua Prieta, proyectada para estar terminada en 2014, aunque por falta de un túnel colector, aún sin licitar, esta planta no captará las aguas de las cuencas al oriente de la ciudad y, por lo tanto, no cubrirá la totalidad de las aguas residuales restante.

Sobre el río Santiago, a la altura de los municipios de El Salto y Juanacatlán, se ha presentado la mayor in- cidencia de contaminación por los efluentes de más de 250 industrias nacionales y transnacionales y de la misma ciudad de Guadalajara, mismas que arrojan aguas sin tratamiento, estudios han registrado la presencia de metales pesados como plomo, cromo, cobalto, mercurio y arsénico en sedimentos del Santiago. ${ }^{5}$

Así describe la autoridad responsable de vigilar y controlar descargas a cuerpos de agua nacionales la situación entre estos dos municipios, sus cabeceras divididas únicamente por un estrecho puente sobre el Santiago a la altura de la otrora turística y viva cascada, el Salto de Juanacatlán, y que albergan conjuntamente una población de más de 150 mil habitantes. ${ }^{6}$ Es aquí donde se inauguró la primera hidroeléctrica para servicio público del país en 1893, seguida en 1896 por la fábrica textil Río Grande, la primera textilera importante en Jalisco que se ubicó en el medio rural. ${ }^{7}$ De aquí, y hacia el lugar donde nace el río, se extiende el corredor industrial Ocotlán-El Salto, el principal del estado y uno de los ejes industriales más importantes del país. Este corredor reúne más de 300 fábricas de empresas mexicanas y transnacionales, donde se destacan los giros químico-farmacéutico, autopartes, metalmecánico, electrónico y alimentos y bebidas. ${ }^{8}$

Aun reconociendo las otras fuentes que deterioran la calidad del agua del río, considero esencial el análisis de las prácticas que favorecen la contaminación industrial del río Santiago por dos razones específicas: primero, los vertidos industriales no han sido abordados de manera directa ni efectiva por los programas oficiales de saneamiento del río y, segundo, estos efluentes son fuente potencial de sustancias de alta toxicidad con posibles afectaciones tanto para la flora y la fauna ribereños como para la salud humana.

\section{Norma obsoleta}

En México existe una norma única para controlar las descargas a cuerpos de aguas nacionales, la NOM-001SEMARNAT-1996, que fija los límites máximos permisibles de contaminantes en tales descargas. Esta norma solamente regula veinte parámetros: ocho parámetros básicos, ocho metales pesados, cianuros, $\mathrm{pH}$, coliformes fecales y parásitos. La norma no logra controlar la contaminación industrial y aun descargas que cumplen con la norma pueden aportar contaminantes tóxicos 
a ríos y otros cuerpos de agua. Un estudio del Instituto Mexicano de Tecnología del Agua (IMTA) afirma que mientras los vertidos industriales de diferentes giros pueden cumplir con la NOM-001, no se toma en cuenta «los contaminantes específicos de cada giro»; por tanto, provoca que «la incorporación de sustancias tóxicas deteriore el ambiente acuático y cause la pérdida de flora y fauna, así como limite los usos del cuerpo receptor». ${ }^{9}$ Para responder a esta deficiencia en la normatividad, el estudio plantea la necesidad de «incluir análisis de toxicidad que puedan identificar aquéllas descargas que introducen sustancias tóxicas, y que no son detectadas por los análisis convencionales». ${ }^{10}$ Este mismo punto fue expuesto por una especialista del área de hidrobiología y evaluación ambiental del IMTA, Yolanda Pica, quien se refiere a la NOM-o01 como una norma «miope» al señalar que «evade de alguna manera las sustancias orgánicas tóxicas, porque no hay forma, ningún parámetro te sugiere la presencia de este tipo de sustancias». ${ }^{11}$ Asevera que, como plantas de tratamiento industriales, se han construido sólo en función de la actual NOM-001 «los cuerpos de agua pues ya tienen una carga de sustancias orgánicas que [...] nunca nadie monitoreó» $y$, a final de cuentas, «nuestros cuerpos de agua están como están». ${ }^{12}$

Queda claro, entonces, que la normatividad actual no logra proteger los cuerpos de agua. En Estados Unidos, la Agencia de Protección al Ambiente (EPA, por sus siglas en inglés) cuenta con distintas normas y lineamientos para cincuenta categorías industriales, regulando los compuestos específicos que descargan cada industria, según sus procesos productivos. En el caso, sólo para dar un ejemplo, de las instalaciones que producen químicos orgánicos, plásticos y fibras sintéticas, están regulados 62 compuestos, de los cuales sólo seis (metales y cianuro) están incluidos en la norma mexicana. Las demás sustancias - bencenos, tolueno, ftalatos - pueden verterse impunemente en este país, a pesar de que están reconocidos sus efectos a la salud. Están instaladas varias industrias de estos giros en el corredor Ocotlán-El Salto.

Peor aún, la aplicación de la norma mexicana es casi inexistente. Un informe de 2013 de la Organización para la Cooperación y el Desarrollo EconómiCOS (OCDE), sobre el desempeño ambiental en el país, reporta que a nivel nacional la Conagua «tiene mucha dificultad para cumplir sus responsabilidades de hacer respetar las regulaciones del agua [...] teniendo 150 ins- pectores para controlar a 475 mil usuarios registrados y muchos más actores ilegales». ${ }^{13}$ Cabe notar que estos usuarios y regulaciones no sólo se refieren al asunto de las descargas, sino a extracciones de agua y usos de zonas federales, entre otros temas. En el caso de las descargas, como parte de una evaluación de 16 normas ambientales por la Secretaría de Medio Ambiente y Recursos Naturales (Semarnat) en 2011, se concluye que la NOM-001-SEMARNAT-1996 «muestra un efecto o impacto nulo». ${ }^{14}$ En términos contundentes, manifiesta el documento que esta norma «no se cumple, lo que representa la libre descarga de contaminantes»; desde la perspectiva de los contaminadores, dice, «es más costoso cumplir con la NOM que enfrentar las consecuencias de la falta de cumplimiento (sanciones)». ${ }^{15}$ Este fenómeno nacional se vive en las aguas del Santiago.

\section{EFLUENTES QUE INCUMPLEN}

En el caso del río Santiago, en concordancia con el programa de saneamiento, las autoridades del agua en Jalisco han afirmado en reiteradas ocasiones que la contaminación industrial es menor que la municipal y que las industrias de la zona cumplen con la normatividad. Raúl Antonio Iglesias Benítez, despedido como director general del Organismo de Cuenca LermaSantiago-Pacífico de la Conagua a finales de 2012 por haber otorgado obras hidráulicas a una empresa en la cual tiene intereses familiares ${ }^{16}$ pudo aseverar que las industrias que regula Conagua «tienen plantas de tratamiento, tienen condiciones de descargas, y a lo que tenemos detectado nosotros [...] están cumpliendo con la normatividad». ${ }^{17}$ Más recientemente, otro representante del organismo, Óscar Herrera Camacho, director de Administración del Agua, estima que 20\% de las empresas incumplen la normatividad que regula las descargas; explica que la Conagua no cuenta con «un ejército de inspectores para estar viendo de forma específica dónde se ubican todas y cada una de las descargas». ${ }^{18}$ De hecho, para toda la región Lerma-Santiago-Pacífico, una zona con una superficie de 191,500 $\mathrm{km}^{2}$, donde habitan más de 22 millones de personas y se genera $17.1 \%$ del Producto Interno Bruto (PIB) nacional, ${ }^{19}$ el «ejército» de la Conagua consta de cuatro inspectores acreditados. ${ }^{20}$

El panorama de cumplimiento o de bajos niveles de incumplimiento no se sustenta al consultar los es- 

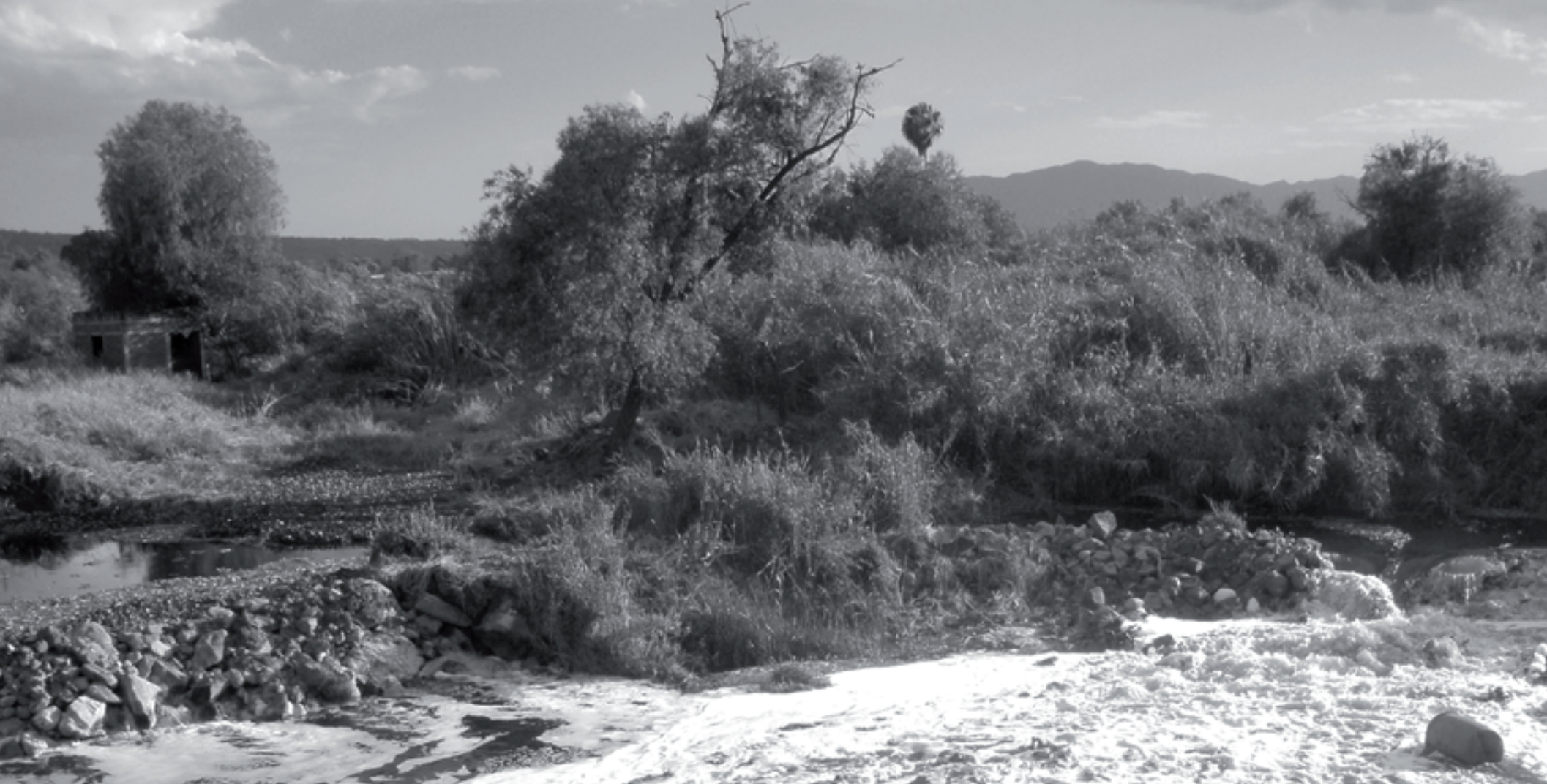

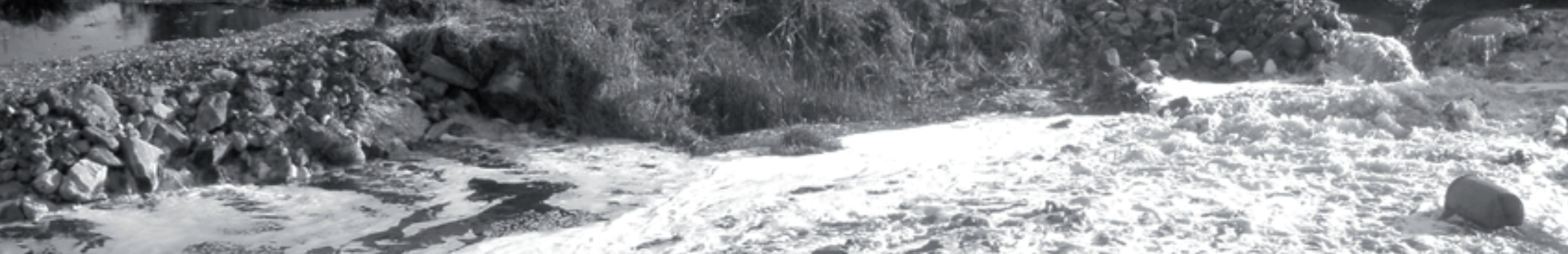
3

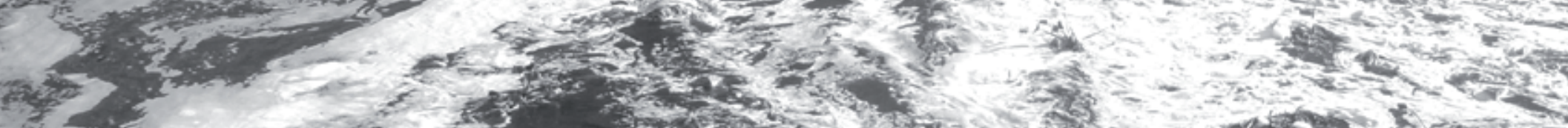

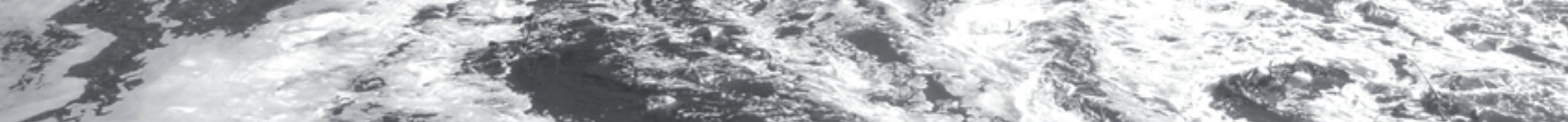

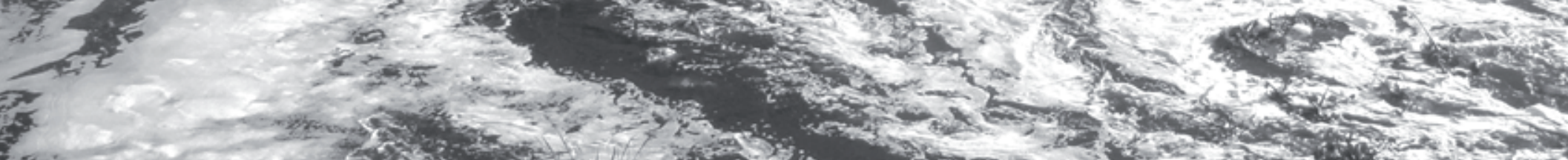

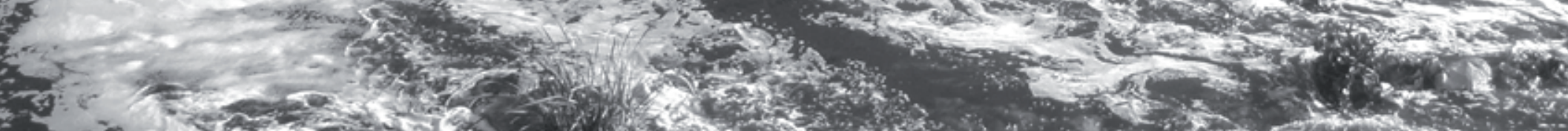

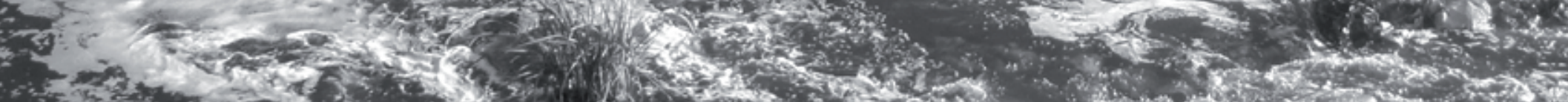

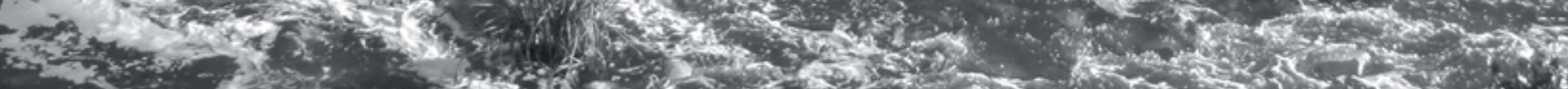

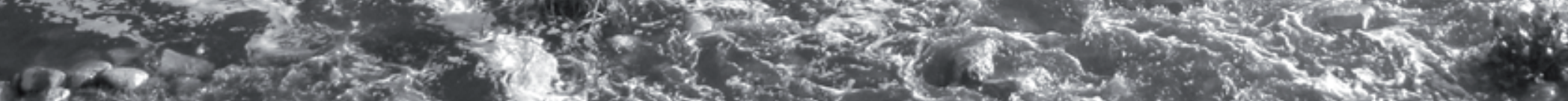

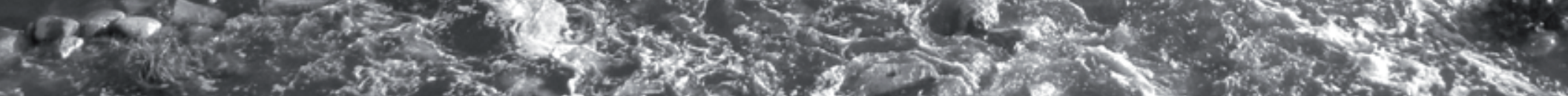

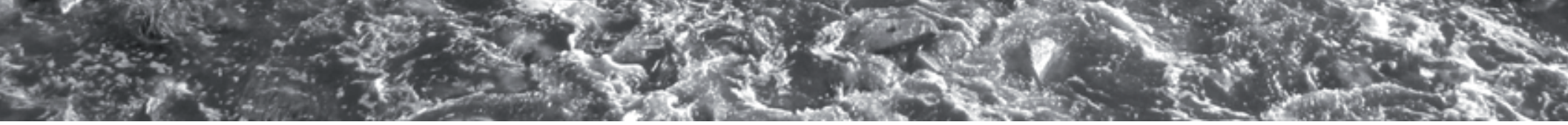


tudios que han analizado los vertidos industriales al río Santiago. El estudio más reciente, que incluye análisis de descargas, fue realizado por el IMTA para la CEA Jalisco; analizó un promedio de 26 descargas industriales en tres campañas de muestreo, entre marzo de 2009 y mayo de 2010. Entre estas descargas estaban las de diversas transnacionales importantes asentadas en la zona que cuentan con plantas de tratamiento, tales como Nestlé, Celanese, Quimikao y Huntsman (antes Ciba Especialidades Químicas). Aun con la normatividad laxa, los niveles de incumplimiento son altos, de hecho se concluye que «las descargas industriales resultaron más contaminantes que las descargas municipales, ya que de 87 a 94\% de las industrias incumplen en al menos uno de los parámetros de la NOM-O01-SEMARNAT-1996». ${ }^{21}$ Además, este estudio buscó identificar la presencia de algunos compuestos sintéticos tanto en descargas como directamente en el río Santiago y sus afluentes, desde su nacimiento hasta la Presa Santa Rosa. El análisis de compuestos orgánicos volátiles y semivolátiles detectó un total de 1,090 sustancias en descargas al río y en muestras de aguas del Santiago y sus afluentes. ${ }^{22}$ Sustancias, o clases de sustancias, encontradas con frecuencia incluyen ftalatos (usados para hacer flexibles los plásticos y con conocidos efectos reproductivos y hepáticos), tolueno (afecta el sistema nervioso), cloroformo (la exposición a largo plazo puede dañar hígado y riñones), benceno (carcinogénico), fenol (afecta al sistema nervioso con la exposición crónica) y también compuestos hormonales..$^{23}$ Este estudio fue dado a conocer por Greenpeace México en mayo de 2012 después de una primera negativa del IMTA para entregarlo.

Para poder medir el impacto de las inspecciones en esta zona, solicité a la Conagua una relación de los infractores que habían violado la NOM-001-SEMARNAT-1996 en la cuenca del río Santiago de 2005 hasta finales de 2011. En una respuesta de 16 páginas de diciembre de 2011, se constata que, primero, el Organismo de Cuenca Lerma-Santiago-Pacífico de la Conagua solicitó una ampliación del plazo para responder y poder contabilizar los documentos; unas semanas después, ya agotado el tiempo fijado legalmente para su respuesta, informaron al Comité de Información de la Conagua que «no se cuenta con la información solicitada». ${ }^{24}$ Insistió el Comité de Información y el Organismo de Cuenca informó que, tras una «búsqueda delicada y por demás entretenida», así como «exhaustiva y minuciosa», no hallaron infractores: «[...] si bien es cierto que se cuenta con Visitas de Inspección en materia de descargas de Aguas Residuales también lo es que por parte de Conagua no existen denuncias ni Procedimientos Administrativos con infracciones por no cumplir o por violentar la NOM-OO1-SEMARNAT-1996». ${ }^{25}$

Así, en un lapso de siete años, sus tareas de inspección no llevaron a ningún proceso contra una sola empresa o persona que descargue fuera de la norma; esto en una cuenca que cubre partes de siete estados (Aguascalientes, Guanajuato, Jalisco, Zacatecas, Nayarit, Durango y San Luis Potosí).

El listado de las inspecciones que Conagua realizó en 2011, publicado en su portal de internet, muestra que ese año en Jalisco se inspeccionaron únicamente 32 descargas, de las cuales sólo 11 eran de empresas (las demás eran de personas físicas, fraccionamientos, ayuntamientos u otras instituciones públicas). Esta cifra subió a 51 descargas inspeccionadas en 2012, 29 de las cuales eran de vertidos industriales. ${ }^{26}$ Así, parece que se realiza un número reducido de inspecciones, que entre 2005 y 2011 no produjeron ningún sancionado.

Entrevistado al respecto, Héctor Castañeda Náñez, quien fungió como director de Cuencas y Sustentabilidad de la CEA Jalisco de 2007 a marzo de 2013, así como gerente de Personal de la Conagua en la administración anterior (2001-2006), explica la no aplicación de esta norma con una palabra: «corrupción». ${ }^{27}$ Sin embargo, amplía el ámbito de esta corrupción al considerar que «la parte de inspección y vigilancia es una partecita de todo un proceso». Señala que tiene que ver tanto con los parámetros incluidos en la norma como las condiciones particulares que se fijan a industrias individuales:

¿Qué sucede si cuando la norma que te regula, regula ciertos parámetros que, por ejemplo, tú en tu proceso no los conoces? Pues entonces eso está muy sencillo, como que te esté doliendo la rodilla izquierda y tú te vayas al doctor y le digas que es la derecha. $\mathrm{O}$, si en condiciones particulares de descarga lo que te fijan son unas cosas que no son las que tú produces, pero no porque se equivoquen sino porque ya lleva una razón de ser. [...] Luego, en la parte procesal, me refiero al levantamiento de actas, si resulta que a la hora que levantas el acta «te equivocas» en alguna cosa a la hora de levantarla, y luego le avisas al usuario que te equivocaste, entonces le das toda la posibilidad de que se ampare y no le haces nada. 
Castañeda no ve con optimismo la normatividad para descargas: «o evoluciona y se fortalece o elimínala, porque de plano lo peor que puedes tener en la vida es un arma legal para hacer algo y no hacer nada».

\section{Reflexiones finAles}

La persistente contaminación del río Santiago en Jalisco por efluentes industriales se relaciona tanto con la normatividad obsoleta que regula tales descargas como con su aplicación casi inexistente. En la práctica, y a pesar de más de una década de protesta social por las organizaciones que conforman el movimiento socioambiental en torno al río Santiago, las fábricas asentadas a sus orillas operan y emiten contaminantes en una condición de impunidad. Estos hechos llaman a cuestionar el funcionamiento (o falta de funcionamiento) de la regulación ambiental en México, al mismo tiempo que sugieren la importancia de interpelar no sólo a los actores gubernamentales, sino directamente a las empresas involucradas, para buscar el saneamiento del río Santiago. Ante la evidente falta de voluntad política para vigilar las emisiones del sector industrial, estrategias dirigidas a las empresas del corredor podrían ser una avenida importante para impulsar mejores condiciones de vida en esta zona. En muchos casos, los actores gubernamentales en México priorizan el crecimiento económico, sacrificando cualquier exigencia de protección ambiental. En la página de internet de la Semarnat se indica que su «visión» es de un país en el que «la ciudadanía abrigue una auténtica preocupación por proteger y conservar el medio ambiente [...] conciliando el desarrollo económico, la convivencia armónica con la naturaleza y la diversidad cultural». ${ }^{28} \mathrm{La}$ autoridad, así, ostenta preocuparse por motivar una especie de cultura ambiental entre sus ciudadanos, pero queda en entredicho su capacidad de «conciliar» ese desarrollo económico con la conservación ambiental. En el caso del río Santiago, parece que esa conciliación implica aceptar ríos tóxicos e ignorar las voces de las poblaciones afectadas.

\section{Referencias}

1 Juan Manuel Durán y Alicia Torres Rodríguez (2006), «Agua potable para Guadalajara; uso y fuentes de abastecimiento bajo un enfoque sustentable» en Itzcóatl Tonatiuh Bravo-Padilla y Fabiola Figueroa (coordinadores), El Proyecto Arcediano y el abastecimiento de la Zona Conurbada de Guadalajara. Análisis de la Universidad de Guadalajara, Guadalajara, Universidad de Guadalajara.

2 Elías González (1989), El Salto, Industria y Urbanización de Guadalajara. Colección: Cuadernos de Difusión Científica 15, Guadalajara, Universidad de Guadalajara, p. 66.

3 Cindy McCulligh, Darcy Tetreault y Paulina Martínez (2012), «Conflicto y contaminación: El movimiento socio-ecológico en torno al Río Santiago», en Heliodoro Ochoa y HansJoachim Bürkner (coordinadores), Gobernanza y gestión del agua en el occidente de México: la metrópoli de Guadalajara, Tlaquepaque, ITESO.

4 Conagua (Comisión Nacional del Agua) (2012), Programa Hídrico Regional Visión 2030: Región Hidrológico-Administrativa VIII Lerma-Santiago-Pacífico, México, Secretaría de Medio Ambiente y Recursos Naturales, p. 26.

5 Conagua (2012), op. cit., p. 25.

6 INEGI (Instituto Nacional de Estadística y Geografía) (2010), Censo de Población y Vivienda 2010, 〈http://www.inegi.org. $\mathrm{mx} /$ sistemas/TabuladosBasicos/preliminares2010.aspx〉.
7 Jorge Durand (1985), «Siglo y medio en el camino de la industrialización», en Patricia Arias (coordinadora), Guadalajara, la Gran Ciudad de la Pequeña Industria, México, Colegio de Michoacán, p. 170.

8 CEAS (Comisión Estatal de Agua y Saneamiento, Jalisco) y Gobierno del Estado de Jalisco (2005), Estudio y Diagnóstico en la Cuenca Baja «El Ahogado» y Monitoreo de la Laguna Cajititlán, Guadalajara, CEAs, p. 6.

9 Pilar Saldaña, Alicia Lerdo de Tejada, Ma. Antonieta Gómez y Rogelio López (2006), La importancia de incluir análisis de toxicidad en descargas industriales y municipales que afectan a los cuerpos receptores, 〈http://www.bvsde.paho.org/bvsaidis/mexico13/068.pdf`, p. 4.

10 Saldaña et al. (2006), op. cit.

11 Comunicación personal, 11 septiembre 2013.

12 Ibid.

13 ocdE (Organización para la Cooperación y el Desarrollo Económico) (2013), oCDE Environmental Performance Reviews: Mexico 2013, ocDE Publishing, p. 50.

14 Semarnat (Secretaría de Medio Ambiente y Recursos Naturales) (2011), Evaluación de Instrumentos Normativos del Sector Ambiental, México, Semarnat, 〈http://biblioteca. semarnat.gob.mx/janium/Documentos/Ciga/Libros2011/ CD001056.pdf», p. 45 . 
15 Semarnat (2011), op. cit.

16 Alejandro Velazco (2013), «Caso Iglesias Benítez: justicia a medias; la SFP omite presentar denuncia penal», La Jornada Jalisco, 21 de marzo, http://www.lajornadajalisco.com. $\mathrm{mx} / 2013 / 03 / 21 /$ caso-iglesias-benitez-justicia-a-mediasla-sfp-omite-presentar-denuncia-penal/>.

17 Jesús Estrada (2009), «Jalisco, con más ojo para polución que la Conagua», Público, 1 de junio, Guadalajara, Grupo Editorial Milenio.

18 Alejandro Velazco (2012), «Incumplen ley federal el 20\% de las empresas que realizan descargas en el Santiago: Conagua», La Jornada Jalisco, 27 de marzo, 〈http://www.lajornadajalisco.com.mx/2012/03/27/incumplen-ley-federalel-20-de-las-empresas-que-realizan-descargas-en-elsantiago-conagua/s.

19 Conagua (2012), op. cit.

20 〈http://www.conagua.gob.mx/Inspector.aspx? $\mathrm{n} 1=5 \& \mathrm{n} 2=38$ \&n3=72〉, consultado agosto 2013.

21 imta (Instituto Mexicano de Tecnología del Agua) y CEA
(Comisión Estatal del Agua, Jalisco) (2011), Actualización del estudio de calidad del agua del Río Santiago (desde su nacimiento en el Lago de Chapala hasta la Presa Santa Rosa), México, IMTA, p. XI-2.

22 IMTA y CEA (2011), op. cit., p. XI-3.

23 〈http://www.osha.gov/sLTC/healthguidelines/phenol/recognition.html.

24 Conagua (Comisión Nacional del Agua) (2011), Respuesta a la solicitud de información del Sistema de Solicitudes de Información del Instituto Federal de Acceso a la Información Pública (SISI IFAI) 1610100185311, 〈www.infomex.org.mx〉, p. 7.

25 Ibid., p. 10.

26 〈http://www.conagua.gob.mx/CONAGUA07/Contenido/Documentos/BASE_ENE-DICIEMBRE_2011.pdf y http://www. conagua.gob.mx/CONAGUA07/Contenido/Documentos/12_ BASE_PVI_ENE-DIC_2012_PUBLICA.pdf .

27 Comunicación personal, 25 febrero 2013.

28 http://www.semarnat.gob.mx/conocenos/Paginas/misionyvision.aspx>.

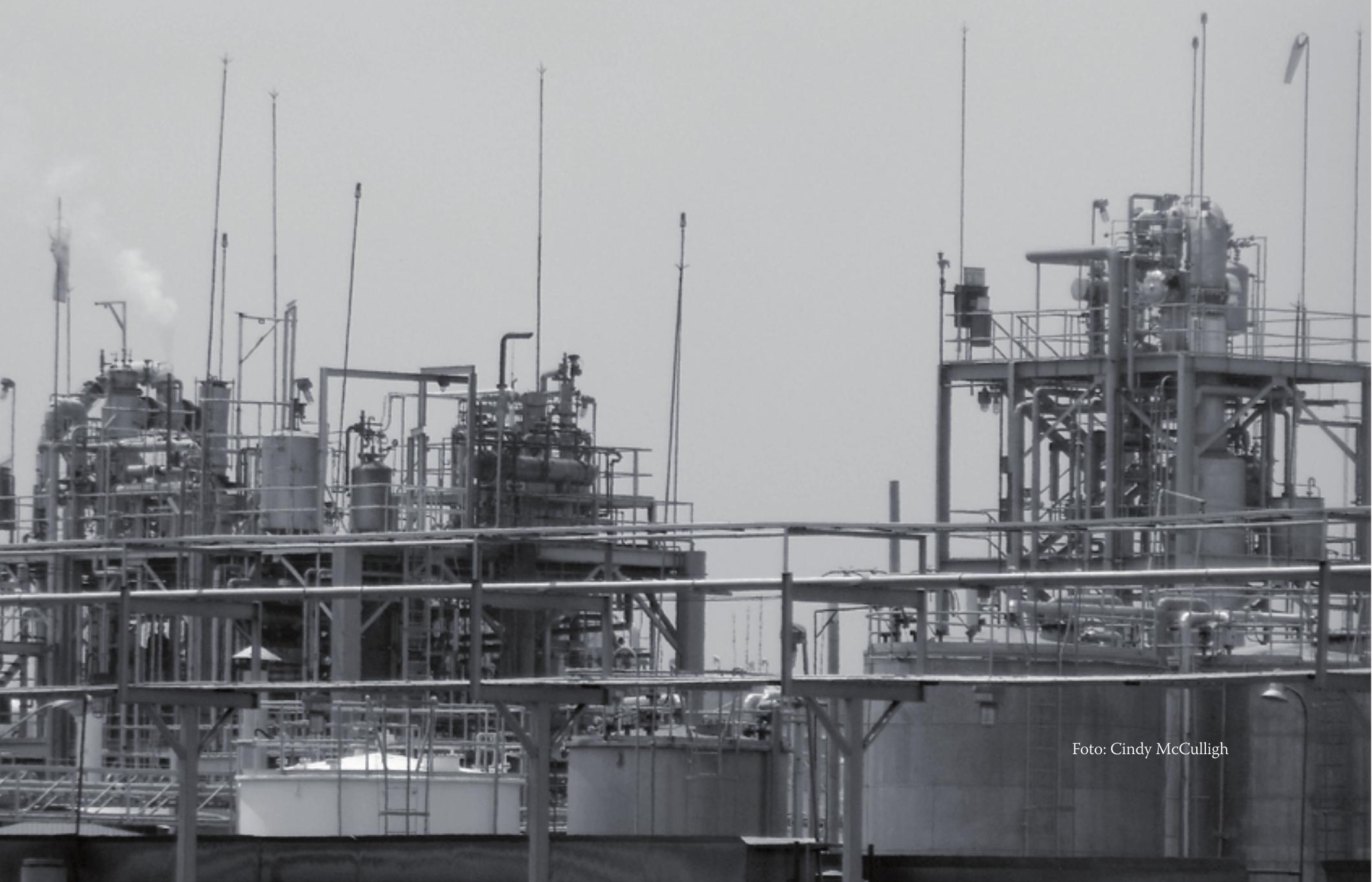

